\title{
Efektifitas Senam Hamil terhadap Kejadian Rupture Perineum pada Ibu Bersalin di Puskesmas Limboto
}

\author{
Juli Gladis Claudia') dan Wirdawaty S Adam²) \\ 1I Jurusan Kebidanan Politekhnik Kesehatan Kemenkes Gorontalo \\ email: juligladisclaudia@yahoo.com \\ 2I Jurusan Kebidanan Politekhnik Kesehatan Kemenkes Gorontalo \\ email: wirdawattyadam@gmail.com
}

\begin{abstract}
Exercise in pregnancy have positive effect on the pregnancy outcome because stumulate to strengthen and maintain elasticity in abdominal muscles and pelvic muscles which was associated with labor that when straining the muscles will relax actively that the head baby will out easily and the pelvic floor muscle is weak, will not easily tear when will give birth. The incidence of perineum rupture at Limboto Community Health Center is 46,7\%. The purpose of this study was to analyze the effectiveness of gymnastics pregnancy against rupture perineum in Maternity at Limboto Community Health Center. The method of research was used pre-experimental research with statistical group comparison design with using chi square test. The population in this study were all thirty pregnant trimester III which amounted 30 people. The sample in this study were 15 case groups and 15 control groups. The variable pregnant exercise was independent variabel and the dependent variable was incidence of perineal rupture. The result of this research by using chi square statistic test was showed t arithmetic 8,571, that mean the respondent who have high pregnancy exercise did not experience rupture perineum. Results $p$-value 0.009 with degree of significance $0.05(p<0.05)$. The conclusion there was a significant effect of pregnancy exercise effectiveness on the incidence of perineal rupture in maternal mothers at Limboto Community Health Center.
\end{abstract}

Keywords: gymnastics pregnancy, rupture perineum

\section{PENDAHULUAN}

Setiap tahun sekitar 160 juta orang di seluruh dunia hamil. Namun sekitar $15 \%$ menderita komplikasi berat, dengan sepertiganya merupakan komplikasi yang mengancam jiwa ibu. Komplikasi ini mengakibatkan kematian lebih dari setengah juta ibu di setiap tahun. Di beberapa Negara risiko kematian ibu lebih $>1$ dalam 10 kehamilan, sedangkan di Negara maju risiko ini kurang dari < 1 dalam 6.000 (Prawirohardjo, 2010). 
Diperkirakan setiap tahun diseluruh dunia terjadi 358.000 kematian ibu dan 99\% terjadi di negara berkembang yang miskin dan sekitar 67\% merupakan sumbangan dari 11 negara termasuk Indonesia. Berdasarkan Survei Demografi Kesehatan Indonesia (SDKI) tahun 2012, Angka Kematian Ibu (AKI) di Indonesia masih tinggi sebesar 359/100.000 kelahiran hidup. Angka kematian ini meningkat dibandingkan hasil SDKI 2007 yang mencapai 228/100.000 kelahiran hidup dan Angka Kematian Bayi (AKB) 34/1.000 kelahiran hidup, sehingga penurunan Angka Kematian Ibu (AKI) di Indonesia masih jauh dari yang diharapkan (Anonimity, 2013).

Penyebab terbesar kematian ibu periode tahun 2010 - 2013 masih tetap sama yaitu Perdarahan Pasca Persalinan (PPP). Sedangkan partus lama tetap menjadi penyumbang kematian ibu terendah (PUSDATIN, 2014). Perdarahan Pasca Persalinan (PPP) adalah perdarahan aktif yang salah satunya berasal dari robekan jalan lahir yang terjadi pada hampir semua persalinan pertama dan tidak jarang terjadi pada persalinan berikutnya. Sebagai akibat persalinan terutama pada seorang primipara, biasa timbul luka pada vulva disekitar introitus vagina yang biasanya tidak terlalu dalam namun kadang menimbulkan perdarahan (Prawirohardjo, 2010).

Senam hamil merupakan salah satu bentuk latihan guna memperkuat dan mempertahankan elastisitas otot - otot dinding perut, ligamen - ligamen, otot dasar panggul yang berhubungan dengan proses persalinan (Hanafi dalam Alfiani, 2013). Senam hamil bermanfaat dalam proses persalinan, memperkuat dan mempertahankan elastisitas pada saat mengejan karena otot-otot dasar panggul dan otot paha bagian dalam mengendur secara aktif sehingga otot dasar panggul yang lemas tidak akan mudah robek saat melahirkan (Hulliana dalam Riswati, 2015).

Data Dinas Kesehatan Provinsi Gorontalo tahun 2013 jumlah kematian ibu sebanyak 52 jiwa atau 252/100.000 kelahiran hidup. Sedangkan pada tahun 2014 mengalami penurunan yaitu dari 52 kasus menjadi 39 kasus kematian ibu yang mencakup perdarahan sebanyak 10 kasus $(25,64 \%)$, hipertensi dalam kehamilan 8 kasus $(20,51 \%)$, infeksi sebanyak 4 kasus $(10,25 \%)$, abortus sebanyak 0 kasus (0\%), partus lama 0 kasus $(0 \%)$ dan 17 kasus $(43,58 \%)$ karena penyakit lain (Dinkes Prov. Gorontalo, 2014).

Pengambilan data awal di Puskesmas Limboto, jumlah ibu hamil yang rutin mengikuti senam hamil sebanyak 51 orang trimester III pada bulan November sampai Desember. Berdasarkan study pendahuluan yang dilakukan pada 6 orang ibu bersalin, 1 orang mengalami robekan perineum derajat II rutin mengikuti senam hamil, 1 orang yang mengalami robekan perineum derajat III yang tidak rutin mengikuti senam hamil, kemudian terdapat 4 orang yang tidak mengalami robekan perineum yang terdiri dari 3 orang yang rutin melakukan senam hamil dan 1 orang yang tidak rutin mengikuti senam hamil. Penelitian ini bertujuan untuk menganalisis efektifitas senam hamil terhadap kejadian rupture perineum pada ibu bersalin di Puskesmas Limboto.

\section{METODE PENELITIAN}

Jenis penelitian yang digunakan dalam penelitian ini adalah penelitian praeksperimen dengan rancangan penelitian statistic group comparison untuk mengidentifikasi efektifitas senam hamil terhadap kejadian rupture perineum pada ibu bersalin. Penelitian ini dilaksanakan di Puskesmas Limboto pada bulan 
Februari hingga Maret 2016. Variable dependent yaitu efektifitas senam hamil dan kejadian rupture perineum. Populasi dalam penelitian ini adalah seluruh ibu hamil trimester III yang berjumlah 30 orang. Sampel dalam penelitian ini yakni seluruh anggota populasi atau seluruh ibu hamil trimester III yang berjumlah 30 orang yang terdiri dari 15 orang kelompok kasus (ibu yang ikut senam hamil) dengan kriteria ibu hamil trimester III, rutin mengikuti atau melakukan senam hamil, tidak memiliki kontra indikasi dan bersedia dijadikan responden, dan 15 orang kelompok kontrol (ibu yang tidak ikut senam hamil).

Data yang digunakan dalam penelitian ini adalah data sekunder dan data primer, dimana data sekunder diperoleh dari buku laporan Puskesmas Limboto, dan data primer yaitu data yang diperoleh langsung dari responden melalui wawancara dan instrumen penelitian. Analisis data menggunakan Chy-Square test untuk melihat pengaruh variabel bebas terhadap variabel terikat. (Sugiono, 2011).

\section{HASIL DAN PEMBAHASAN}

3.1 Analisis Karakteristik Ibu Hamil

Tabel 1 Karakteristik Senam Hamil dan Rupture Perineum Pada Wanita Hamil Trimester III di Ppuskesmas Limboto

\begin{tabular}{lcc}
\hline Jenis Variabel & \multicolumn{2}{c}{ Jumlah } \\
\cline { 2 - 3 } & $\mathrm{n}$ & $\%$ \\
\hline Umur (tahun) & 8 & 26,7 \\
$<20$ dan $>35$ & 22 & 73.3 \\
$20-35$ & & \\
Paritas & 17 & 56,7 \\
Primipara & 13 & 43,3 \\
Multipara & & \\
Pendidikan & 7 & 23,3 \\
SD & 3 & 10,0 \\
SMP & 11 & 36,7 \\
SMA & 9 & 30,0 \\
Sarjana & 12 & 40,0 \\
Pekerjaan & 6 & 20,0 \\
IRT & 5 & 16,7 \\
PNS & 7 & 23,3 \\
Honorer & & 50,0 \\
Wiraswasta & 15 & 50,0 \\
Senam Hamil & 15 & 46,7 \\
Dilakukan & & 53,3 \\
Tidak dilakukan & 14 & 100 \\
Rupture Perineum & 16 & \\
Rupture & 30 & \\
Tidak rupture & & \\
\hline Total & & \\
\hline
\end{tabular}

Tabel 1 menunjukkan sebagian besar ibu berusia 20 - 35 tahun sebanyak 22 orang $(73,3 \%)$, paritas ibu sebagian besar berkategori primipara sebanyak 17 orang $(56,7 \%)$, tingkat pendidikan ibu sebagian besar pada tingkat pendidikan SMA 11 orang $(36,7 \%)$, pekerjaan ibu sebagian besar sebagai IRT 
12 orang $(40 \%)$, perbandingan antara ibu yang melakukan senam hamil dan tidak melakukan senam hamil adalah sama yakni masing - masing $15 \mathrm{ibu}$ (50\%), dan sebagian besar ibu tidak mengalami rufture uteri yakni 16 responden $(53.3 \%)$.

3.2 Analisis Hubungan Senam Hamil Dengan Kejadian Rufture Perineum Tabel 2 Analisis Hubungan Senam Hamil Dengan Kejadian Rupture Perineum Pada Ibu Hamil

\begin{tabular}{|c|c|c|c|c|c|c|c|c|}
\hline \multirow{3}{*}{$\begin{array}{l}\text { Rupture } \\
\text { Perineum }\end{array}$} & \multicolumn{4}{|c|}{ Senam Hamil } & \multirow{2}{*}{\multicolumn{2}{|c|}{ Jumlah }} & \multirow{3}{*}{$\begin{array}{c}t \\
\text { hitung }\end{array}$} & \multirow{3}{*}{$\begin{array}{c}p \\
\text { value }\end{array}$} \\
\hline & \multicolumn{2}{|c|}{$\mathrm{Ya}$} & \multicolumn{2}{|c|}{ Tidak } & & & & \\
\hline & $\mathrm{n}$ & $\%$ & $\mathrm{n}$ & $\%$ & $\mathrm{n}$ & $\%$ & & \\
\hline Rupture & 3 & 21,4 & 11 & 78,57 & 14 & 46,7 & & \\
\hline Tidak Rupture & 12 & 75,0 & 4 & 25,0 & 16 & 53,3 & 8,571 & 0,009 \\
\hline Jumlah & 15 & 50,0 & 15 & 50,0 & 30 & 100 & & \\
\hline
\end{tabular}

Tabel 2 uji statistik menunjukkan bahwa ibu yang melakukan senam hamil lebih banyak tidak mengalami rupture perineum yaitu 12 orang $(75 \%)$ sedangkan ibu yang tidak melakukan senam hamil lebih banyak mengalami rupture perineum yaitu 11 orang $(78,57 \%)$. Nilai $t$ hitung menunjukkan 8,571 artinya responden yang melakukan senam hamil lebih banyak tidak mengalami rupture perineum dibandingkan dengan yang tidak melakukan senam hamil. Nilai $p$ value $=0,009(\mathrm{p}<0,05)$ sehingga dapat dikatakan bahwa senam hamil memiliki hubungan yang signifikan dengan kejadian rupture perineum pada ibu hamil, dengan kata lain senam hamil terbukti efektif dalam mencegah terjadinya rupture perineum pada ibu bersalin.

Hasil penelitian ini sejalan dengan penelitian Riswati (2015) di Wilayah Kerja Puskesmas Tegal Rejo Kota Salatiga, yang menyatakan ada hubungan yang signifikan antara senam hamil dengan kejadian robekan perineum. Senam hamil bermanfaat dalam proses persalinan, salah satunya yaitu melatih dan menguasai tekhnik pernafasan yang berperan sangat penting selama kehamilan dan dalam proses persalinan. Kegunaan dari latihan dasar pernafasan yaitu melatih ketenangan, mempercepat sirkulasi darah, serta mencukupi kebutuhan oksigen bagi ibu dan janinnya. Selain itu senam hamil merupakan salah satu cara untuk membuat ibu hamil nyaman dan mudah dalam persalinan dan mengakibatkan peningkatan kadar norepinefrin di dalam otak, sehingga meningkatkan daya kerja dan mengurangi rasa tegang (Maryani, 2011). Menurut Riswati (2015) manfaat yang tak kalah penting yaitu memperkuat dan mempertahankan elastisitas otot-otot dasar panggul, dan otot paha bagian dalam. Dengan demikian proses kontraksi dan relaksasi yang berhubungan dengan proses persalinan dapat mengurangi rasa sakit saat proses persalinan. Salah satu latihan menguatkan dan mempertahankan elastisitas adalah latihan menguatkan otot dasar panggul yang kegunaannya adalah melemaskan otot dasar panggul yang kuat dalam keadaan yang santai, pada saat mengejam otot akan mengendur secara aktif sehingga kepala bayi akan keluar dengan mudah, dengan demikian otot dasar panggul yang lemas, tidak akan mudah robek saat akan melahirkan (Hulliana, 2008).

Ibu yang aktif melakukan senam hamil masih ada beberapa ibu yang mengalami robekan perineum, hal ini disebabkan karena faktor lain yaitu berat 
lahir janin yang lebih besar, usia ibu, posisi ibu saat persalinan, persalinan pertama, proses mengejan yang terlalu awal. Kejadian robekan juga akan meningkat jika bayi dilahirkan terlalu cepat dan tidak tepat dalam mengatur kecepatan kelahiran bayi, keterampilan penolong persalinan juga merupakan salah satu faktor yang menyebabkan rupture perineum karena penolong yang tidak dapat mencegah terjadinya pengeluaran kepala yang tiba-tiba, akan mengakibatkan laserasi yang hebat dan tidak teratur, bahkan dapat meluas sampai sphincter ani dan rectum.

Ibu yang tidak mengalami robekan perineum dimungkinkan karena pengaturan posisi yang benar pada saat persalinan, senam hamil, perineum message, dan yoga prenatal (Aprilia, 2011). Ibu yang mengikuti senam hamil dapat bermanfaat dalam proses persalinan yaitu ibu dapat melatih ketenangan menghadapi proses persalinan, memperkuat dan mempertahankan elastisitas pada saat mengejan otot-otot dasar panggul dan otot paha bagian dalam mengendur secara aktif sehingga otot dasar panggul yang lemas tidak akan mudah robek saat melahirkan (Huliana, 2008).

\section{KESIMPULAN DAN SARAN}

Ibu hamil yang rutin melakukan senam hamil sebagian besar tidak mengalami rupture perineum sehingga dapat dikatakan bahwa senam hamil memiliki hubungan yang signifikan dengan kejadian rupture perineum pada ibu hamil. Upaya yang dapat dilakukan untuk mengurangi angka kejadian rupture perineum yakni dengan cara menambah pengetahuan ibu melalui konseling ataupun lebih meningkatkan sosialisasi tentang pelaksanaan senam hamil dan manfaat pada saat proses persalinan apabila rutin mengikuti senam hamil. Selain itu upaya yang dapat dilakukan yakni dengan cara membagikan CD dan membuat leaflet senam hamil sehingga ibu hamil tidak hanya melakukan senam hamil di Puskesmas saja, tetapi juga dapat melakukannya di rumah.

\section{REFERENSI}

Anonimity. 2012. Senam hamil sebagai upaya untuk memperlancar proses persalinan di Rumah Sakit Kasih Ibu Surakarta. http://ejurnalinfokes.apikescm.ac.id.

2012. Data Angka Kematian Ibu Menurut SDKI, http:/ / nasional.sindonews.com/read/2013/09/25/15/787480/datasdki-2012-angka-kematian-ibu-melonjak.

. 2013. Hubungan antara teknik meneran dengan ruptura perineum pada ibu bersalin yang selama kehamilan mengikuti senam hamil. http://digilib.unipasby.ac.id.

. 2015. Hubungan senam hamil terhadap terjadinya robekan perineum pada ibu bersalin primigravida di wilayah kerja Puskesmas Tegalrejo Kecamatan Agromulyo Kota Salatiga. http:// perpusnwu.web.id.

Harun. 2014. Hubungan berat badan bayi baru lahir dengan rupture perineum spontan pada persalinan primipara Di RSUD. Prof. Dr. H. Aloei Saboe Kota Gorontalo. Karya Tulis Ilmiah Jurusan Kebidanan. Poltekes Kemenkes Gorontalo: Gorontalo 
Manuaba. 2010. Ilmu kebidanan, penyakit kandungan, dan KB. EGC. Jakarta. Maryunani. 2011. Senam hamil senam nifas dan terapi musik. Trans Info Media. Jakarta.

Nugroho. 2010. Buku ajar obstetri untuk mahasiswa kebidanan. Nuha Medika. Yogyakarta.

Notoadmojo S. 2010. Metodologi penelitian kesehatan. Rineka Cipta. Jakarta.

Rosdiana. 2013. Faktor-faktor terjadi terjadinya rupture perineum pada ibu bersalin normal di Puskesmas pelayanan obstetri neonatal emergency dasar (PONED) Darul Imarah Aceh besar tahun 2013. Skripsi Jurusan DIV Kebidanan. Banda Aceh.

Salese. 2014. Faktor-Faktor yang berhubungan dengan terjadinya rupture perineum pada persalinan normal Di Puskesmas Limba B. Karya Tulis Ilmiah Jurusan Kebidanan. Poltekes Kemenkes Gorontalo. Gorontalo.

Sugiyono . 2011. Statistika untuk penelitian. Alfabeta. Bandung. 